\title{
Novel Insights in the Diagnosis of Cushing's Syndrome
}

\author{
Krystallenia I. Alexandraki Ashley B. Grossman \\ Department of Endocrinology, St. Bartholomew's Hospital, London, UK
}

\section{Key Words}

Salivary cortisol $\cdot$ Late-night salivary cortisol .

Bed-time salivary cortisol · Midnight serum cortisol ·

Dexamethasone suppression test $\cdot$ Cushing's syndrome

\begin{abstract}
Cushing's syndrome (CS) results from sustained pathologic hypercortisolism. Increased identification of cyclical CS and the similarities between the metabolic syndrome and mild CS has resulted in an increased prevalence of CS, necessitating more accurate diagnostic tests to screen and diagnose CS in its earliest stages. Many studies have examined the utility of resistance to steroid feedback by the dexamethasone suppression tests and increases in secretion assessing 24hour urinary free cortisol; however, the most sensitive indicator is the loss of circadian rhythmicity. Therefore, midnight sleeping cortisol is undoubtedly an extremely sensitive indicator of CS but impractical for screening purposes. In this situation assessment late-night salivary cortisol (NSC) is being increasingly investigated as a simple and convenient outpatient procedure. Salivary cortisol has also been used in stimulation or suppression tests because of the detection of rapid changes in cortisol concentration. This paper discusses the effectiveness of SC as a putative accurate, stress-free, and non-invasive sampling procedure. Some studies have shown no difference between tests while others demonstrated a higher sensitivity of SC, while the combination of tests seems to increase their diagnostic value. However, the different as-
\end{abstract}

says used for SC estimation and the variable types of control groups in the published studies render a comparison of studies difficult. In conclusion, NSC measurement is increasingly being used as a first-line test for CS, but we recommend that local centres establish their own normative ranges, and there is still a place for the more traditional tests to confirm the diagnosis.

Copyright $\odot 2010$ S. Karger AG, Basel

\section{Introduction}

Cushing's syndrome (CS) results from sustained pathologic hypercortisolism. When the presentation is florid, diagnosis is usually straightforward and biochemical tests are needed only to confirm the clinical suspicion [1]. However, the incidence of mild cases of CS appears to be increasing, and the similarities between the metabolic syndrome (MS) and CS [2] require a more meticulous investigation of CS in populations with features such as obesity, hypertension, diabetes and the polycystic ovarian syndrome [3-7]. Some of these features may be associated with biochemical tests suggestive of CS, so-called pseudo-Cushing. Moreover, the recognition that cyclic CS is not uncommon [8] renders the diagnosis particularly difficult in the 'trough' period of activity [9]. These considerations were in part the stimulus for the Endocrine Society to recently publish a clinical practice guideline for the diagnosis of CS [10].

\section{KARGER}

Fax +41613061234 E-Mail karger@karger.ch www.karger.com

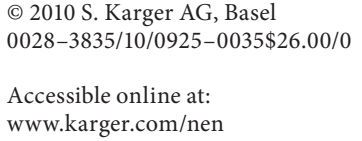

Ashley Grossman

Department of Endocrinology

St. Bartholomew's Hospital

London EC1A 7BE (UK)

Tel. +44 207601 8343, Fax +44 207601 8505, E-Mail a.b.grossman@ qmul.ac.uk 
The first step in the diagnosis of CS involves the confirmation of hypercortisolism and only secondarily does its aetiology need to be identified. This step is the most critical since it is related to the number of the patients that will unnecessarily be involved in laborious and costly tests, or that will be misdiagnosed as being inappropriately healthy resulting in a delayed diagnosis with deleterious long-term consequences from the sustained hypercortisolism [11]. Previously, 24-hour urinary free cortisol measurement (UFC; at least 2-4 measurements), the 1 -mg overnight dexamethasone suppression test (1-DST) and the low-dose DST (LDDST, $0.5 \mathrm{mg}$ every $6 \mathrm{~h}$ for 2 days) have been utilised as the first-line diagnostic tests, but more recently late-night salivary cortisol (NSC) measurement is becoming increasingly used in many centres [10]. However, in individuals with normal results in these initial tests and in whom there remains strong suspicion (e.g. where there is an adrenal lesion or the symptoms and signs are cyclic), when there is evidence of progression, or when only one of test results is abnormal and clinical suspicion is low, further evaluation at a later stage is crucial to confirm or exclude the diagnosis. It has been suggested that in these particularly difficult cases a dexamethasone-corticotropin-releasing hormone test is mandated, but recent data have supported our own contention that this is excessively complex and rarely provides useful information over and above the standard LDDST $[12,13]$. Lack of circadian rhythmicity is certainly one of the most sensitive indicators of the presence of CS, so an inpatient midnight serum cortisol (MNC) test may be extremely helpful, but this is clearly impractical for screening. It has to be underlined that exogenous hypercortisolism should be continuously and meticulously excluded at each diagnostic step [10].

It must be emphasised that despite these best efforts the diagnosis of hypercortisolism still remains challenging. The diagnostic tests based on a failure of feedback regulation were originally designed for more obvious cases than those increasingly being seen, and the thresholds for serum cortisol levels have inevitably changed as the assays have become modified and more sensitive. Specifically, the conventional use of the 1-DST, a marker of resistance of the hypothalamo-pituitary-adrenal axis to glucocorticoid feedback, may still be insufficiently sensitive to detect mild cases of CS [14, 15], particularly in Cushing's disease (CD). In our series a 09:00 h serum cortisol of $<50 \mathrm{nmol} / \mathrm{l}(1.8 \mu \mathrm{g} / \mathrm{dl})$ at both 24 and $48 \mathrm{~h}$ was $98 \%$ sensitive in the diagnosis of CS [16] but it is not possible to say with absolute certainty whether very mild cases of CS, particularly CD, were missed. The measurement of UFC levels, a marker of increased synthesis of cortisol exceeding the binding capacity of corticosteroid-binding globulin (CBG), even with more accurate assay techniques and in the most compliant patients, has limited sensitivity, particularly in cases of mild hypercortisolism $[14,17]$. Theoretically, it would seem likely that the MNC level should be the most sensitive indicator for CS, as we and others have argued for the sleeping MNC many years ago $[18,19]$, but a midnight salivary cortisol (SC) is clearly much more practical for screening purposes: salivary cortisol (SC) has been considered to be a sensitive and specific screening modality to detect rapid changes in the free biologically-active cortisol concentration [10]. Moreover, in specific cases the direct measurement of serum free cortisol (FC) levels assessment might also be promising. This review will focus on these new diagnostic tools.

\section{Salivary Cortisol}

Cortisol circulates in blood largely bound, approximately $90 \%$, to CBG, with additionally approximately $7 \%$ bound to albumin and with the much smaller amount of unbound hormone responsible for its metabolic effects $[20,21]$. The free unbound cortisol diffuses freely through the acinar cells of salivary glands. Since binding proteins are absent from saliva, the concentration of cortisol in the saliva is in equilibrium with serum FC [22] and represents approximately $4 \%$ of the total circulating serum cortisol [23]. The measurement of cortisol in saliva is thus a simple, reproducible [24-26], stress-free, non-invasive and reliable test to evaluate the circadian rhythm of the hypothalamo-pituitary-adrenal axis [27]. There are a variety of simple methods to obtain saliva samples without stress, making this a robust test applicable to many different experimental and clinical situations, in outpatients as well as in inpatients. Saliva is collected either by expectoration into a plastic tube or by placing a cotton pledget (salivette) in the mouth and chewing for 1-2 min. The sample is stable at room for 7 days or at refrigerator temperature for several weeks, and can be mailed to a reference laboratory $[10,28]$.

Interestingly, the first studies of $\mathrm{SC}$ were published approximately 30 years ago [29], but this approach has increased in popularity over the last decade and is beginning to replace the more traditional tests of hypercortisolaemia [10]. However, since different commercially available methods have been used over this long period of its evaluation, it is important to be aware of the different results published, producing varying thresholds or cut- 
Table 1. Methodological characteristic of the more recent studies which investigated the clinical value of NSC in adult populations with CS, with suspicion of CS and features of MS

\begin{tabular}{|c|c|c|c|c|c|c|}
\hline First author & $\begin{array}{l}\mathrm{CS}(\mathrm{CD} \text {, adrenal } \\
\text { origin, ectopic) }\end{array}$ & $\begin{array}{l}\text { Times of } \\
\text { collection } \\
\mathrm{h}\end{array}$ & $\begin{array}{l}\text { Set- } \\
\text { ting }\end{array}$ & $\begin{array}{l}\text { Assay used (method } \\
\text { of saliva collection) }\end{array}$ & $\begin{array}{l}\text { Reference range/cut-offs, nmol/l } \\
\text { (method of selection) }\end{array}$ & $\begin{array}{l}\text { Sensitivity (\%)/ } \\
\text { specificity (\%) }\end{array}$ \\
\hline Raff, 1998 [23] & $39(30,5,4)$ & 23:00 & $\mathrm{O}$ & RIA (salivettes) & 3.6 (2 SD above mean of controls) & $92 / 97$ \\
\hline Castro, $1999[34]$ & $33(20,13,0)$ & 23:00 & I & $\begin{array}{l}\text { RIA (expectoration } \\
\text { in tubes) }\end{array}$ & 7.7 (90th of obese) & $\begin{array}{l}\text { 93/89 (vs. obese patients) } \\
100 / 88 \text { (vs. normal subjects) }\end{array}$ \\
\hline $\begin{array}{l}\text { Papanicolaou, } 2002 \\
\text { [35] }\end{array}$ & $122(98,12,12)$ & $\begin{array}{l}23: 30 / 24: 00 \\
\text { bedtime }\end{array}$ & $\mathrm{I} / \mathrm{O}$ & $\begin{array}{l}\text { RIA (expectoration } \\
\text { in tubes) }\end{array}$ & 15.2 (100\% specificity) & $93 / 100$ \\
\hline Putignano, 2003 [40] & $41(33,7,1)$ & 24:00 & I & RIA (salivettes) & $\begin{array}{l}9.7 \text { (ROC to optimize sensitivity } \\
\text { and specificity) }\end{array}$ & $93 / 93$ \\
\hline Yaneva, 2004 [41] & $63(37,17,9)$ & 24:00 & $\mathrm{I} / \mathrm{O}$ & RIA (salivettes) & $\begin{array}{l}5.52 \text { (maximize sensitivity with } \\
\text { good specificity) }\end{array}$ & $100 / 96$ \\
\hline Viardot, 2005 [24] & $12(5,3,4)$ & 23:30 & $\mathrm{O}$ & RIA (salivettes) & 6.1 (ROC to optimize sensitivity) & $100 / 100$ \\
\hline Trilck, 2005 [32] & $120(120,0,0)$ & 22:00 & $\mathrm{O}$ & RIA (salivettes) & $\begin{array}{l}\text { 16-20 years: } 5.24 \\
21-60 \text { years: } 4.41 \\
\text { (optimize sensitivity/specificity) }\end{array}$ & $\begin{array}{l}94.7 / 90.5(16-20 \text { years }) \\
100 / 90.9(21-60 \text { years })\end{array}$ \\
\hline Friedman, 2007 [36] & $24(24,0,0)$ & 23:00 & $\mathrm{O}$ & ELISA (NR) & 4.3 (2 SD above mean of controls) & $45 / 95$ \\
\hline Baid, 2007 [31] & $0 / 261$ obese & bedtime & $\mathrm{O}$ & $\begin{array}{l}\text { RIA/LC-MS/MS } \\
\text { (salivettes) }\end{array}$ & $\begin{array}{l}\text { RIA: } 4.7 \text {; } \\
\text { LC-MS/MS: } 2.8\end{array}$ & $\begin{array}{l}\text { RIA: } 85-86 \\
\text { LC-MS/MS: 92-94 }\end{array}$ \\
\hline Kidambi, 2007 [17] & 11 mild CS $(9,2,0)$ & $\begin{array}{l}23: 00 \\
24: 00\end{array}$ & $\mathrm{O}$ & ELISA (salivettes) & 4.3 (2 SD above mean of controls) & NA \\
\hline Caetano, 2007 [76] & 3 subclinical CS & 23:00 & $\mathrm{O}$ & RIA (salivettes) & 6.98 (upper quintile) & $\begin{array}{l}\text { 92/93 (vs. obese/nonobese/ } \\
\text { pseudo-Cushing's patients }\end{array}$ \\
\hline Restituto, 2008 [52] & $22(\mathrm{NR})$ & $24: 00$ & I & ELISA (salivettes) & 2.21 (ROC) & $88 / 82$ \\
\hline Doi, 2008 [55] & $27(5,18,4)$ & 23:00 & I & RIA (salivettes) & $\begin{array}{l}5.79 \text { (ROC) } \\
4.97 \text { (ROC) }\end{array}$ & $\begin{array}{l}93 / 100(5.79) \\
100 / 89(4.97)\end{array}$ \\
\hline Vilar, 2008 [77] & $74(46,21,7)$ & 23:00-24:00 & $\mathrm{O}$ & RIA (salivettes) & 8.5 (previously studied) & $100 / \mathrm{NR}$ \\
\hline Masserini, 2009 [54] & 22 SCSA & $23: 00$ & $\mathrm{O}$ & $\begin{array}{l}\text { immunofluoro- } \\
\text { metrically (salivettes) }\end{array}$ & $0.68-5.1$ (95th of normal) & $23 / 88$ \\
\hline Nunes, 2009 [26] & 13 CS, 23 SCSA & $\begin{array}{l}22: 00-24: 00 \\
\text { bedtime }\end{array}$ & $\mathrm{I} / \mathrm{O}$ & RIA (salivettes) & $\begin{array}{l}12 \text { (ROC to identify overt CS) } \\
4.8 \text { (ROC to diagnose SCSA) }\end{array}$ & $\begin{array}{l}\text { 100/100 (for CS) } \\
\text { 77/69 (inpatients with SCSA) } \\
\text { 77/68 (outpatients with SCSA) }\end{array}$ \\
\hline Cardoso, 2009 [25] & $21(11,9,1)$ & 23:00 & $\mathrm{O}$ & $\begin{array}{l}\text { RIA (expectoration } \\
\text { in tubes) }\end{array}$ & $3.8 \mathrm{nmol} / \mathrm{l}(\mathrm{ROC})$ & $100 / 97.5$ \\
\hline
\end{tabular}

$\mathrm{I}=$ Inpatients; $\mathrm{O}=$ outpatients; $\mathrm{NA}=$ not applicable; $\mathrm{NR}=$ not reported; $\mathrm{ROC}=$ receiver operating characteristic curves; $\mathrm{SCSA}=$ subclinical secreting adenomas.

offs, and to interpret them appropriately (table 1; fig. 1) $[30,31]$. The first assays used for SC measurements were those of radioimmunoassay (RIA), but the more recently validated assays used in the United States are an enzymelinked immunosorbent assay (ELISA) and an assay performed by tandem mass spectrometry (LC-MS/MS) [31]. The RIA and LC-MS/MS have been directly compared in an obese population, where the overall agreement in paired samples was $88 \%$, with better agreement for nor- mal values than abnormal ones. Furthermore, RIA values were consistently higher than LC-MS/MS results, particularly in older and diabetic subjects; hence, the specificity of RIA was found to be significantly lower than that of LC-MS/MS. On the other hand, the enzyme immunoassay found higher SC values than the RIA, but RIA gave results much closer to the expected value of an independently-created cortisol stock solution diluted in saliva [30]. Overall, different cut-offs have been reported with 


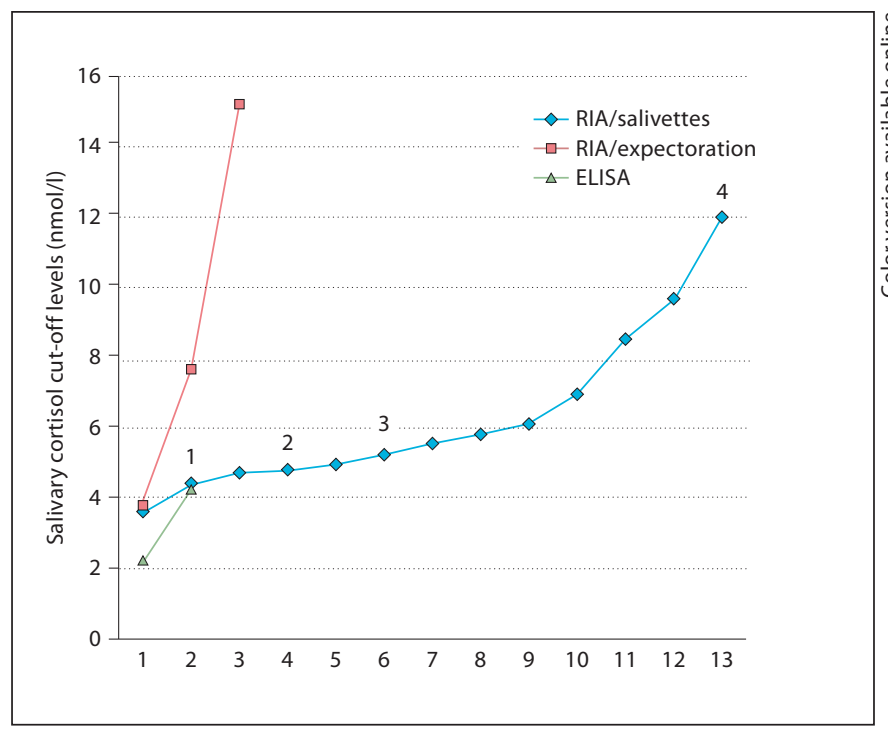

Fig. 1. Salivary cortisol 'cut-off' values in the studies of table 1 according to the method used to assay cortisol and collect saliva. Three studies used RIA and direct expectoration with cut-offs in the range 3.8-15.2 nmol/l; 10 studies used RIA and salivettes (in three of these studies two cut-off values were reported) with cutoffs in the range 3.6-12 nmol/l; and two studies used ELISA and salivettes with cut-offs in the range $2.21-4.3 \mathrm{nmol} / \mathrm{l}$. Cut-off 1 : this cut-off was selected for the age group 21-60 years; cut-off 2 : this cut-off was selected to differentiate patients with subclinical cortisol-secreting adrenal adenoma; cut-off 3: this cut-off was selected for the age group 16-20 years; cut-off 4: this cut-off was selected to differentiate patients with overt Cushing's syndrome.

regards to different control groups used, with some authors proposing that reference ranges might be related to age (as is the case for IGF-1) or to other comorbidities such as obesity, type 2 diabetes or hypertension $[32,33]$.

\section{Late-Night, Midnight or Bedtime Salivary Cortisol}

An overlap in morning SC and FC has been well documented between patients with CS and normal subjects, precluding such morning sampling from being useful in the diagnosis of CS [23, 24, 34-36]. Laudat et al. [37] found no overlap in SC measured at 20:00 h between normal subjects and patients with CS. Since it was shown that the discrimination between CS and normal or obese groups improves in the late evening [34], all the recent studies have focussed on 23:00 h, midnight or 'bedtime' SC for outpatients. It is of interest that no statistical difference was seen inpatients with sampling at 23:30 or 24:00 h [35].
Two recent meta-analyses included studies that enrolled participants referred for evaluation of possible CS $[38,39]$. In this way, the authors tried to assess the accuracy of this test (by means of sensitivity and specificity) in the 'real-life' patient when there is diagnostic uncertainty, eliminating the bias of most studies conducted in patients with florid CS where the only concern was related to the aetiology and not to the confirmation of CS $[23,24,34-36,40,41]$.

Assessment of UFC, MNC, 1-DST and the LDDST were also evaluated in one of these published meta-analyses [38]. As expected, UFC and 1-DST had the most evidence (in terms of most studies) exploring their use for the detection of CS, with only few studies reporting on the use of MNC and NSC tests. This finding was also supported by a more recent review [42]. There was also only limited evidence for the use of these tests in combination to both identify and exclude patients with CS. Regarding the NSC, from 4 studies the analysis generated a likelihood ratio for a positive test [LR(+): the ratio of the probability of increased NSC levels if there is CS (true positive) to the probability of increased NSC levels if there is not CS (false positive)] equal to 8.8 (95\% CI 3.5-21.8) and a LR for a negative test [LR(-), the ratio of the probability of low NSC levels when there is CS (false negative) to the probability of low NSC levels when there is not CS (true negative)] equal to 0.07 (95\% CI 0.00-1.20) [43]. The second and more recent meta-analysis [39] investigated only the NSC and reported an LR(+) equal to 21 (95\% CI 1043), LR(-) 0.08 (95\% CI 0.02-0.32), while its pooled sensitivity for the diagnosis of CS was 92\% (95\% CI 88-94\%) and its specificity $96 \%$ (95\% CI 94-97\%). It is obvious from these studies that SC tests therefore perform as well as any of the more conventional assessments.

\section{Limitations of the Meta-Analyses}

The moderate to high heterogeneity which was found in both meta-analyses could be explained by the limitations of pooled data [39]. Regarding the specific studies included, only rarely were the number of cases with 'no conclusive diagnosis' reported, even when evaluated in centres of excellence. In addition, patients with CS were not always of the same severity. Clearly, the more severe CS is in a group of patients, the better is the value of sensitivity assessed. Of some interest is the fact that in some studies the NSC was performed as an inpatient while in others it was an outpatient procedure. Clearly, for screening purposes only the outpatient setting is of value. However, two studies directly comparing these two groups found no clear differences, suggesting that normative 
data in an inpatient setting could be applied equally to outpatients $[26,35]$.

Regarding the method of evaluation, the different assays and different cut-offs used precluded the use of universal thresholds (fig. 1). However, since the diagnostic performance of NSC does not appear to be dependent on the specific cut-off values used in each study, the performance of the test seems to be relatively independent of the assay as long as thresholds are determined and used according to the specific assay and study population [39].

\section{Salivary Cortisol Assessed in Other Circumstances}

It has been speculated that substituting saliva for serum cortisol determination may simplify the stimulation or suppression tests. In healthy subjects, the SC response paralleled that of total serum cortisol following insulininduced hypoglycemia, intramuscular tetracosactrin/ synacthen and intravenous dexamethasone infusion. However, a lag in secretion of the free fraction from the plasma into the saliva was observed when sampling over short intervals. Overall, the absolute changes in cortisol levels from the basal value were greater in saliva than in plasma [44].

In the 1-DST, SC was found to be a good substitute for serum cortisol measurement $[34,45,46]$ with regards to sensitivity and specificity [34]. No overlap was observed between patients with CS and normal subjects for cut-off values around $2.4-3.1 \mathrm{nmol} / 1[34,37,47,48]$. However, an overlap was seen between obese and CS patients [34], and this test has so far not gained favour as a screening test [24].

The utility of SC was also compared to serum cortisol and plasma ACTH during the LLDST, high-dose DST ( $2 \mathrm{mg}$ every $6 \mathrm{~h}$ for 2 days) and very-high dose DST (6 mg every $6 \mathrm{~h}$ for 1 day) [49]. SC showed more profound suppression than serum cortisol or plasma ACTH in a doseresponsive pattern. This might be explicable by the fact that CBG binding of plasma cortisol limits the amount of free diffusible cortisol, with the consequent fall in cortisol levels in saliva showing a more rapid and significant response than total serum cortisol levels, better mirroring physiological cortisol secretion changes in suppression tests $[49,50]$. If this is true, more stringent suppression criteria should be accepted when FC markers are used [49].

Regarding stimulation tests performed in patients with CS, in the corticotropin-releasing hormone test, SC was revealed to be as good as serum cortisol or plasma ACTH measurement in differentiating patients with CS [49].

Salivary Cortisol in Cushing's Syndrome

\section{Combinations of Diagnostic Tests}

When combining the results of both $23: 00 \mathrm{~h}$ collection and the 1-DST, both using SC, the sensitivity (100\%) was higher than that of either test performed individually [34]; this may be a promising combination when investigating cases of very mild CS [26]. A similar improvement was reported in sensitivity combining elevated NSC and elevated UFC $[23,40]$. This latter combination was comparable to the combination of MNC and UFC [40]. Both MNC and NSC correctly identified the only patient with CS who had normal UFC levels, with an overall concordance of $92 \%$ (90.3\% correct and concordant diagnoses, $1.7 \%$ incorrect and concordant diagnoses), and $8 \%$ discordant diagnoses [40]. Of the latter, MNC suggested the correct diagnosis in 8 cases, and NSC in 16 cases, but this did not differ statistically. Considering the daily variability in baseline cortisol secretion [51], an additional test might minimise any laboratory error.

Correlation of Salivary Cortisol Concentrations with the Other Parameters of Hypercortisolism

A strong and significant correlation between serum cortisol and SC values has been reported, particularly in the CS group $[45,52]$, even after dexamethasone administration $[24,25,45]$. This is principally true for the patient group [34] but sometimes it can been seen in the whole population when it is large $[34,49,53]$. However, UFC was correlated with 23:00 h SC in patients with CS but not in healthy subjects or the other control groups, probably reflecting the cortisol levels in excess of the CBG saturation $[23,24,41,49,54]$ in all but one study [25]: this finding was confirmed by the absence of any correlation in normal subjects and in a large obese population [31]. A strong correlation between NSC and MNC confirms that NSC is a good surrogate for MNC [25, 26, $35,55]$ in patients with CS and in normal subjects $[25,56]$.

\section{Clinical Validity of Salivary Cortisol Assessment in Specific Cases}

Some published case reports have supported the clinical value of SC measurement in specific clinical scenarios. Thus, one patient with a psychotic illness was reported who refused to have blood sampling but agreed to SC testing [57]. In another case, CS was confirmed by assessing SC after 1-DST in a patient with an undetectable UFC because of renal failure [58]. In a well-designed study of a patient with cyclic CD, similar patterns of responses of UFC and SC measurement were found [56]; SC would be 
most convenient to follow these patients as it could be performed immediately upon the 'cycling-in' of CS. In particular, in cases of cyclic CD complicated by the distance between patient and hospital, the measurement of SC was documented to be an extremely valuable tool [59].

Importantly, the ease of collecting the saliva samples and the possibility of performing the procedure on an outpatient basis, along with the evidence provided for the diagnosis of CS, all support the use of SC testing in children to differentiate CS from obesity. High sensitivity (100\%) and specificity (95.2\%) for the diagnosis of CS have been reported for the performance of NSC and 1-DST SC assessment [48]. Since the diagnostic accuracies of NSC and UFC per square metre were the same (93\%), measurement of SC seems to represent a 'friendlier' diagnostic tool for the paediatric population [53].

NSC has been found of limited clinical value in the diagnosis of mild CS such as the case of subclinical cortisol-secreting adenomas (SCSA) $[17,26,54]$. This finding, along with the fact that these patients have a normal UFC and an abnormal 1-DST, may imply that such patients have a preserved circadian rhythm, and it is difficult to understand if there is a degree of adrenal autonomy. However, in one reported patient with SCSA, in less than $50 \%$ of 16 saliva samples collected were the NSC concentrations above the cut-off value [41]. The use of lower thresholds in these settings might improve its diagnostic performance, but only its combination with 1-DST seems to increase its diagnostic clinical value [26]. Hence, the recent guidelines for the diagnosis of CS suggest use of the 1-DST or MNC, rather than UFC and NSC, in patients suspected of having mild CS because of an adrenal incidentaloma [10].

\section{Pitfalls in Salivary Cortisol Assessment}

There are certain issues that should be very carefully considered regarding saliva sampling and interpreting the results of saliva tests. In terms of the method of saliva collection, the use of salivette devices results in lower cortisol concentrations than those collected from passive expectoration, but are better correlated with total cortisol and FC levels [60, 61]. Furthermore, since salivary glands express $11 \beta$-hydroxysteroid dehydrogenase type $2(11 \beta$ HSD2) [62], it is theoretically possible that liquorice or chewing tobacco (both of which contain the inhibitor glycyrrhizic acid, an inhibitor of $11 \beta-\mathrm{HSD} 2)$ may have produced a falsely elevated NSC. Patients also have to be advised to avoid cigarette smoking on the day of collec- tion [63], or vigorous tooth brushing [64], performing the test on a quiet evening at home to avoid stress-induced increases of SC (although the 'stress' of watching sport on TV has been claimed to be of little relevance) $[23,65,66]$. After an abnormal SC, the collection technique and current medications/lotions should be meticulously revised and an additional screening test is required before concluding that significant hypercortisolism is present [31]. Saliva collection procedures can be problematic in special situations: insufficiency of saliva samples in patients with CS may occur because of dehydration, somnolence/unconsciousness or insufficient cooperation [24].

\section{Clinical Validity of Serum Free Cortisol Assessment in Specific Cases}

Despite the early identification of techniques to measure FC $[67,68]$, this test has never gained a place in the diagnostic armamentarium of CS since no obvious advantage was documented, and because of its limited value in the differential diagnosis of hypercortisolism [69]. In general, to overcome the clinical situations where unbound cortisol levels had to be specified, the use of the indirect free cortisol index (FCI) has been used [70]. In some (albeit rare) situations, such as in cases of CBG deficiency [71] FC has been useful, or in cases of patients who are poorly compliant and SC is not recommended [24]. FC might also be as helpful as SC measurement in the early stages of pregnancy when oestrogen-induced increased CBG levels are accompanied by elevated plasma cortisol levels [21]. The superiority of FC might be due to altered compliance in pregnant women because of problems such as vomiting. In late pregnancy [24, 72] and in women taking oral contraceptives, SC and FC levels are both elevated [73]. Finally, we have recently shown that the measurement of FC appears to be a promising biochemical marker of hypercortisolism in patients with adrenal carcinoma treated with mitotane [74]. This adrenolytic drug greatly increases plasma CBG levels through its action on the liver [75], invalidating total cortisol levels and FCI.

\section{Conclusions}

As the loss of circadian rhythmicity is one of the most sensitive diagnostic features of CS, many studies have explored the value of NSC as an initial diagnostic screening test. It appears to be as accurate on an outpatient as on an 
inpatient basis, and thus appears to be a highly convenient simple measurement with acceptable specificity. However, it is important to note the particular assay in use, and to develop thresholds or cut-off values in the specific population being screened. Where possible, it is ideal for the centre to develop its own normative ranges. In addition, at this point, we would advise that additional testing should be performed in patients showing results indicative of CS, and our current best protocol is to admit the patient for a sleeping MNC and LDDST. Whether these requirements will continue as we gain more experience with this test remains to be seen. Whatever we con- clude, at present we would highlight the need for a series of tests for the diagnosis of CS on a background of clinical suspicion, and with knowledge of any pointers to diagnostic confusion such as unexplained osteoporosis, depressive illness or alcoholism, or various types of interfering drugs. The diagnosis is probabilistic rather than algorithmic in all but the most obvious and severe cases.

\section{Disclosure Statement}

The authors have nothing to disclose.

\section{References}

-1 Newell-Price J, Bertagna X, Grossman AB, Nieman LK: Cushing's syndrome. Lancet 2006;367:1605-1617.

- 2 Anagnostis P, Athyros VG, Tziomalos K, Karagiannis A, Mikhailidis DP: Clinical review: the pathogenetic role of cortisol in the metabolic syndrome: a hypothesis. J Clin Endocrinol Metab 2009;94:2692-2701.

- 3 Leibowitz G, Tsur A, Chayen SD, Salameh M, Raz I, Cerasi E, Gross DJ: Pre-clinical Cushing's syndrome: an unexpected frequent cause of poor glycaemic control in obese diabetic patients. Clin Endocrinol (Oxf) 1996; 44:717-722.

4 Omura M, Saito J, Yamaguchi K, Kakuta Y, Nishikawa T: Prospective study on the prevalence of secondary hypertension among hypertensive patients visiting a general outpatient clinic in Japan. Hypertens Res 2004;27: 193-202.

5 Catargi B, Rigalleau V, Poussin A, RonciChaix N, Bex V, Vergnot V, Gin H, Roger P, Tabarin A: Occult Cushing's syndrome in type-2 diabetes. J Clin Endocrinol Metab 2003;88:5808-5813.

-6 Reincke M, Nieke J, Krestin GP, Saeger W, Allolio B, Winkelmann W: Preclinical Cushing's syndrome in adrenal 'incidentalomas': comparison with adrenal Cushing's syndrome. J Clin Endocrinol Metab 1992;75: 826-832.

-7 Kaltsas GA, Korbonits M, Isidori AM, Webb JA, Trainer PJ, Monson JP, Besser GM, Grossman AB: How common are polycystic ovaries and the polycystic ovarian syndrome in women with Cushing's syndrome? Clin Endocrinol (Oxf) 2000;53:493-500.

-8 Alexandraki KI, Kaltsas GA, Isidori AM, Akker SA, Drake WM, Chew SL, Monson JP, Besser GM, Grossman AB: The prevalence and characteristic features of cyclicity and variability in Cushing's disease. Eur J Endocrinol 2009;160:1011-1018.
\$9 Meinardi JR, Wolffenbuttel BH, Dullaart RP: Cyclic Cushing's syndrome: a clinical challenge. Eur J Endocrinol 2007;157:245254.

10 Nieman LK, Biller BM, Findling JW, NewellPrice J, Savage MO, Stewart PM, Montori VM: The diagnosis of Cushing's syndrome: an Endocrine Society Clinical Practice Guideline. J Clin Endocrinol Metab 2008;93: 1526-1540.

11 Etxabe J, Vazquez JA: Morbidity and mortality in Cushing's disease: an epidemiological approach. Clin Endocrinol (Oxf) 1994;40: 479-484.

12 Yanovski JA, Cutler GB Jr, Chrousos GP, Nieman LK: The dexamethasone-suppressed corticotropin-releasing hormone stimulation test differentiates mild Cushing's disease from normal physiology. J Clin Endocrinol Metab 1998;83:348-352.

13 Martin NM, Dhillo WS, Banerjee A, Abdulali A, Jayasena CN, Donaldson M, Todd JF, Meeran K: Comparison of the dexamethasone-suppressed corticotropin-releasing hormone test and low-dose dexamethasone suppression test in the diagnosis of Cushing's syndrome. J Clin Endocrinol Metab 2006;91:2582-2586.

14 Vilar L, Freitas Mda C, Faria M, Montenegro R, Casulari LA, Naves L, Bruno OD: Pitfalls in the diagnosis of Cushing's syndrome. Arq Bras Endocrinol Metabol 2007;51:12071216.

15 Wood PJ, Barth JH, Freedman DB, Perry L, Sheridan B: Evidence for the low dose dexamethasone suppression test to screen for Cushing's syndrome - recommendations for a protocol for biochemistry laboratories. Ann Clin Biochem 1997;34:222-229.

16 Kaltsas GA, Isidori AM, Skelly RH, Kola B, Monson JP, Grossman AB, Besser GM: The value of the low dose dexamethasone suppression test in the differential diagnosis of hyperandrogenism in women. J Clin Endocrinol Metab 2003;88:2634-2643.
17 Kidambi S, Raff H, Findling JW: Limitations of nocturnal salivary cortisol and urine free cortisol in the diagnosis of mild Cushing's syndrome. Eur J Endocrinol 2007;157:725731.

18 Papanicolaou DA, Yanovski JA, Cutler GB Jr, Chrousos GP, Nieman LK: A single midnight serum cortisol measurement distinguishes Cushing's syndrome from pseudo-Cushing states. J Clin Endocrinol Metab 1998;83: 1163-1167.

19 Newell-Price J, Trainer P, Perry L, Wass J, Grossman A, Besser M: A single sleeping midnight cortisol has $100 \%$ sensitivity for the diagnosis of Cushing's syndrome. Clin Endocrinol (Oxf) 1995;43:545-550.

20 Dunn JF, Nisula BC, Rodbard D: Transport of steroid hormones: binding of 21 endogenous steroids to both testosterone-binding globulin and corticosteroid-binding globulin in human plasma. J Clin Endocrinol Metab 1981;53:58-68.

21 Brien TG: Human corticosteroid binding globulin. Clin Endocrinol (Oxf) 1981;14: 193-212.

22 Kahn JP, Rubinow DR, Davis CL, Kling M, Post RM: Salivary cortisol: a practical method for evaluation of adrenal function. Biol Psychiatry 1988;23:335-349.

23 Raff H, Raff JL, Findling JW: Late-night salivary cortisol as a screening test for Cushing's syndrome. J Clin Endocrinol Metab 1998;83:2681-2686.

24 Viardot A, Huber P, Puder JJ, Zulewski H, Keller U, Müller B: Reproducibility of nighttime salivary cortisol and its use in the diagnosis of hypercortisolism compared with urinary free cortisol and overnight dexamethasone suppression test. J Clin Endocrinol Metab 2005;90:5730-5736.

$\checkmark 25$ Cardoso EM, Arregger AL, Tumilasci OR, Contreras LN: Diagnostic value of salivary cortisol in Cushing's syndrome (CS). Clin Endocrinol (Oxf) 2009;70:516-521. 
26 Nunes ML, Vattaut S, Corcuff JB, Rault A, Loiseau H, Gatta B, Valli N, Letenneur L, Tabarin A: Late-night salivary cortisol for diagnosis of overt and subclinical Cushing's syndrome in hospitalized and ambulatory patients. J Clin Endocrinol Metab 2009;94: 456-462.

-27 Vining RF, McGinley RA, Maksvytis JJ, Ho KY: Salivary cortisol: a better measure of adrenal cortical function than serum cortisol. Ann Clin Biochem 1983;20:329-335.

-28 Chen YM, Cintrón NM, Whitson PA: Longterm storage of salivary cortisol samples at room temperature. Clin Chem 1992;38:304.

29 Hiramatsu R: Direct assay of cortisol in human saliva by solid phase radioimmunoassay and its clinical applications. Clin Chim Acta 1981;117:239-249.

-30 Raff H, Homar PJ, Burns EA: Comparison of two methods for measuring salivary cortisol. Clin Chem 2002;48:207-208.

-31 Baid SK, Sinaii N, Wade M, Rubino D, Nieman LK: Radioimmunoassay and tandem mass spectrometry measurement of bedtime salivary cortisol levels: a comparison of assays to establish hypercortisolism. J Clin Endocrinol Metab 2007;92:3102-3107.

>32 Trilck M, Flitsch J, Lüdecke DK, Jung R, Petersenn S: Salivary cortisol measurement - a reliable method for the diagnosis of Cushing's syndrome. Exp Clin Endocrinol Diabetes 2005;113:225-230.

$\checkmark 33$ Liu H, Bravata DM, Cabaccan J, Raff H, Ryzen E: Elevated late-night salivary cortisol levels in elderly male type 2 diabetic veterans. Clin Endocrinol (Oxf) 2005;63:642649.

\34 Castro M, Elias PC, Quidute AR, Halah FP, Moreira AC: Out-patient screening for Cushing's syndrome: the sensitivity of the combination of circadian rhythm and overnight dexamethasone suppression salivary cortisol tests. J Clin Endocrinol Metab 1999;84: 878-882.

-35 Papanicolaou DA, Mullen N, Kyrou I, Nieman LK: Nighttime salivary cortisol: a useful test for the diagnosis of Cushing's syndrome. J Clin Endocrinol Metab 2002;87: 4515-4521.

>36 Friedman TC, Zuckerbraun E, Lee ML, Kabil MS, Shahinian H: Dynamic pituitary MRI has high sensitivity and specificity for the diagnosis of mild Cushing's syndrome and should be part of the initial workup. Horm Metab Res 2007;39:451-456.

-37 Laudat MH, Cerdas S, Fournier C, Guiban D, Guilhaume B, Luton JP: Salivary cortisol measurement: a practical approach to assess pituitary-adrenal function. J Clin Endocrinol Metab 1988;66:343-348.

-38 Elamin MB, Murad MH, Mullan R, Erickson D, Harris K, Nadeem S, Ennis R, Erwin PJ, Montori VM: Accuracy of diagnostic tests for Cushing's syndrome: a systematic review and metaanalyses. J Clin Endocrinol Metab 2008;93:1553-1562.
9 Carroll T, Raff H, Findling JW: Late-night salivary cortisol for the diagnosis of Cushing syndrome: a meta-analysis. Endocr Pract 2009;15:335-342.

40 Putignano P, Toja P, Dubini A, Pecori Giraldi F, Corsello SM, Cavagnini F: Midnight salivary cortisol versus urinary free and midnight serum cortisol as screening tests for Cushing's syndrome. J Clin Endocrinol Metab 2003;88:4153-4157.

41 Yaneva M, Mosnier-Pudar H, Dugué MA, Grabar S, Fulla Y, Bertagna X: Midnight salivary cortisol for the initial diagnosis of Cushing's syndrome of various causes. J Clin Endocrinol Metab 2004;89:3345-3351.

42 Raff H: Utility of salivary cortisol measurements in Cushing's syndrome and adrenal insufficiency. J Clin Endocrinol Metab 2009; 94:3647-3655

43 Bewick V, Cheek L, Ball J: Statistics review 13: receiver operating characteristic curves. Crit Care 2004;8:508-512.

44 Kahn SE, Maxwell JU, Barron JL: Salivary cortisol assessment in the evaluation of hypothalamic-pituitary-adrenal function. S Afr Med J 1984;65:843-846.

45 Bonnin R, Villabona C, Rivera A, Guillen E, Sagarra E, Soler J, Navarro MA: Is salivary cortisol a better index than free cortisol in serum or urine for diagnosis of Cushing syndrome? Clin Chem 1993;39:1353-1354.

46 Hägg E, Olsson T, Grankvist K: Salivary cortisol during an overnight dexamethasone suppression test using a simple saliva collection device. Horm Metab Res 1990;22:553554.

-47 Barrou Z, Guiban D, Maroufi A, Fournier C, Dugué MA, Luton JP, Thomopoulos P: Overnight dexamethasone suppression test: comparison of plasma and salivary cortisol measurement for the screening of Cushing's syndrome. Eur J Endocrinol 1996;134:93-96.

48 Martinelli CE Jr, Sader SL, Oliveira EB, Daneluzzi JC, Moreira AC: Salivary cortisol for screening of Cushing's syndrome in children. Clin Endocrinol (Oxf) 1999;51:67-71.

49 Castro M, Elias LL, Elias PC, Moreira AC: A dose-response study of salivary cortisol after dexamethasone suppression test in Cushing's disease and its potential use in the differential diagnosis of Cushing's syndrome. Clin Endocrinol (Oxf) 2003;59:800-805.

50 Cope ClL Black EG: The reliability of some adrenal function tests. Br Med J 1959;ii:11171122.

51 Flack MR, Oldfield EH, Cutler GB Jr, Zweig $\mathrm{MH}$, Malley JD, Chrousos GP, Loriaux DL, Nieman LK: Urine free cortisol in the highdose dexamethasone suppression test for the differential diagnosis of the Cushing syndrome. Ann Intern Med 1992;116:211-217.

52 Restituto P, Galofré JC, Gil MJ, Mugueta C, Santos S, Monreal JI, Varo N: Advantage of salivary cortisol measurements in the diagnosis of glucocorticoid related disorders. Clin Biochem 2008;41:688-692.
53 Gafni RI, Papanicolaou DA, Nieman LK: Nighttime salivary cortisol measurement as a simple, noninvasive, outpatient screening test for Cushing's syndrome in children and adolescents. J Pediatr 2000;137:30-35.

54 Masserini B, Morelli V, Bergamaschi S, Ermetici F, Eller-Vainicher C, Barbieri AM, Maffini MA, Scillitani A, Ambrosi B, BeckPeccoz P, Chiodini I: The limited role of midnight salivary cortisol levels in the diagnosis of subclinical hypercortisolism in patients with adrenal incidentaloma. Eur J Endocrinol 2009;160:87-92.

55 Doi M, Sekizawa N, Tani Y, Tsuchiya K, Kouyama R, Tateno T, Izumiyama H, Yoshimoto T, Hirata Y: Late-night salivary cortisol as a screening test for the diagnosis of Cushing's syndrome in Japan. Endocr J 2008;55: 121-126.

56 Hermus AR, Pieters GF, Borm GF, Verhofstad AA, Smals AG, Benraad TJ, Kloppenborg PW: Unpredictable hypersecretion of cortisol in Cushing's disease: detection by daily salivary cortisol measurements. Acta Endocrinol (Copenh) 1993;128:428-432.

57 Myhill PC, Sillars BA, Starkstein S, Annus T, Yeap BB: Reduction in salivary cortisol concentration correlates with resolution of psychosis in Cushing's syndrome. J Neuropsychiatry Clin Neurosci 2008;20:113-115.

58 Issa BG, Page MD, Read G, John R, DouglasJones A, Scanlon MF: Undetectable urinary free cortisol concentrations in a case of Cushing's disease. Eur J Endocrinol 1999; 140:148-151.

59 Mosnier-Pudar H, Thomopoulos P, Bertagna X, Fournier C, Guiban D, Luton JP: Longdistance and long-term follow-up of a patient with intermittent Cushing's disease by salivary cortisol measurements. Eur J Endocrinol 1995; 133:313-316.

60 Poll EM, Kreitschmann-Andermahr I, Langejuergen Y, Stanzel S, Gilsbach JM, Gressner A, Yagmur E: Saliva collection method affects predictability of serum cortisol. Clin Chim Acta 2007;382:15-19.

61 Kidd S, Midgley P, Lone N, Wallace AM, Nicol M, Smith J, McIntosh N: A re-investigation of saliva collection procedures that highlights the risk of potential positive interference in cortisol immunoassay. Steroids 2009;74:666-668.

62 Smith RE, Maguire JA, Stein-Oakley AN, Sasano H, Takahashi K, Fukushima K, Krozowski ZS: Localization of 11 beta-hydroxysteroid dehydrogenase type II in human epithelial tissues. J Clin Endocrinol Metab 1996; 81:3244-3248.

63 Badrick E, Bobak M, Britton A, Kirschbaum C, Marmot M, Kumari M: The relationship between alcohol consumption and cortisol secretion in an aging cohort. J Clin Endocrinol Metab 2008;93:750-757. 
-64 Kivlighan KT, Granger DA, Schwartz EB, Nelson V, Curran M, Shirtcliff EA: Quantifying blood leakage into the oral mucosa and its effects on the measurement of cortisol, dehydroepiandrosterone, and testosterone in saliva. Horm Behav 2004;46:39-46.

65 Guechot J, Fiet J, Passa P, Villette JM, Gourmel B, Tabuteau F, Cathelineau G, Dreux C: Physiological and pathological variations in saliva cortisol. Horm Res 1982;16:357-364.

-66 Garde AH, Persson R, Hansen AM, Osterberg K, Ørbaek P, Eek F, Karlson B: Effects of lifestyle factors on concentrations of salivary cortisol in healthy individuals. Scand J Clin Lab Invest 2009;69:242-250.

67 Dennis PM: The determination of free plasma cortisol. N Z Med J 1963;62:478-481.

-68 Kley HK, Bartmann E, Krüskemper HL: A simple and rapid method to measure nonprotein-bound fractions of cortisol, testosterone and oestradiol by equilibrium dialysis: comparison with centrifugal filtration. Acta Endocrinol (Copenh) 1977;85:209219.
69 Friedman TC, Yanovski JA: Morning plasma free cortisol: inability to distinguish patients with mild Cushing syndrome from patients with pseudo-Cushing states. J Endocrinol Invest 1995;18:696-701.

70 le Roux CW, Chapman GA, Kong WM, Dhillo WS, Jones J, Alaghband-Zadeh J: Free cortisol index is better than serum total cortisol in determining hypothalamic-pituitary-adrenal status in patients undergoing surgery. J Clin Endocrinol Metab 2003;88:2045-2048.

71 Watanobe H, Nigawara T, Nasushita R, Sasaki S, Takebe K: A case of cyclical Cushing's disease associated with corticosteroid-binding globulin deficiency: a rare pitfall in the diagnosis of Cushing's disease. Eur J Endocrinol 1995;133:317-319.

72 Allolio B, Hoffmann J, Linton EA, Winkelmann W, Kusche M, Schulte HM: Diurnal salivary cortisol patterns during pregnancy and after delivery: relationship to plasma corticotrophin-releasing-hormone. Clin Endocrinol (Oxf) 1990;33:279-289.

73 Meulenberg PM, Ross HA, Swinkels LM, Benraad TJ: The effect of oral contraceptives on plasma-free and salivary cortisol and cortisone. Clin Chim Acta 1987;165:379-385.
74 Alexandraki KI, Kaltsas GA, le Roux CW, Fassnacht M, Ajodha S, Christ-Crain M, Akker SA, Drake WM, Edwards R, Allolio B, Grossman AB: Assessment of serum free cortisol levels in patients with adrenocortical carcinoma treated with mitotane: a pilot study. Clin Endocrinol (Oxf) 2010;72:305311.

75 van Seters AP, Moolenaar AJ: Mitotane increases the blood levels of hormone-binding proteins. Acta Endocrinol (Copenh) 1991; 124:526-533.

76 Caetano MS, Silva Rdo C, Kater CE: Increased diagnostic probability of subclinical Cushing's syndrome in a population sample of overweight adult patients with type 2 diabetes mellitus. Arq Bras Endocrinol Metabol 2007;51:1118-1127.

77 Vilar L, Freitas MC, Naves LA, Canadas V, Albuquerque JL, Botelho CA, Egito CS, Arruda MJ, Silva LM, Arahata CM, Agra R, Lima LH, Azevedo M, Casulari LA: The role of non-invasive dynamic tests in the diagnosis of Cushing's syndrome. J Endocrinol Invest 2008;31:1008-1013. 